\title{
Incidence of Concussions and Injuries Among Quidditch Players
}

\author{
Som Singh ${ }^{1,2}$ | Alexander Nadeau ${ }^{1}$ | Shipra Singh MD ${ }^{1,3}$ | Christopher \\ Shaw MD ${ }^{1}$
}

${ }^{1}$ University of Missouri Kansas City School of Medicine, Kansas City, Missouri, USA.

${ }^{2}$ US Quidditch, Lynnwood, Washington, USA.

${ }^{3}$ QUICK Research Institute, Kansas City, Missouri, USA.

${ }^{4}$ Central Michigan University College of Medicine, Mount Pleasant, Michigan, USA.

\section{Correspondence}

Som Singh

Email: somsingh@mail.umkc.edu

Publication Date

January 4, 2021

MJM 2021 (19) 2

\section{McGill \\ Journal of Medicine}

www.mjmmed.com

\section{c) (i) (2) (2)}

This work is licensed under a Creative Commons BY-NC-SA 4.0 International License.

\begin{abstract}
Purpose: To evaluate the rates of concussion and injury in quidditch, a high-contact sport growing in worldwide participation. Methods: A systematic review of the MEDLINE database was performed according to Preferred Reporting Items for Systematic Reviews and Meta-Analyses (PRIMSA) guidelines for all studies reporting on concussion and/or injury rates in quidditch epidemiology. Results: Five studies were identified that had been published in the last 15 years on the concussion and injury rates among quidditch players worldwide. Each of these five studies included a concussion analysis and two included overall epidemiological rates. Conclusions: Injury rates seen in the two studies were found to be lower than those seen in other high-contact sports. There is a need to further study concussion symptoms among this understudied population.

KEYWORDS

Quidditch, Injury, Concussion, Epidemiology, Systematic Review
\end{abstract}

\section{1 | BACKGROUND}

Established in 2005, quidditch is a fast-paced, highcontact sport which has seen explosive growth over the past decade, with thousands of players in over 39 countries now engaging in the sport (1). Despite this immense popularity, quidditch is behind other high- contact sports cohorts in terms of international attention to safety and concussion risk.

Unlike most high-contact sports, the game is played in a gender-inclusive format (2). The unique nature of this game requires clinicians to develop a compounded knowledge of treatment compared to other sports, which are usually separated into men's and women's 
divisions. Like rugby, the game is traditionally played in a 7-on-7 format with players wearing little protective equipment. In the US version of gameplay, each player serves a specific position (e.g. Chaser, Beater, Keeper) and can experience collisions during play (3). All players are currently mandated to wear a mouthguard during gameplay, and quidditch matches have a leaguesanctioned medical staff for injury management (1). Despite the injury-risk attention, the literature on this sport is scarce. The purpose of this article is to outline the current epidemiological literature of quidditch sport injuries and propose future innovations for injury surveillance.

\section{2 | METHODOLOGY}

In May 2020, a systematic review of literature was performed on MEDLINE, Google Scholar, and the Cochrane Database of Systematic Reviews for quidditch injury epidemiological studies. The search was performed using the Preferred Reporting Items for Systematic Reviews and Meta-Analyses (PRISMA) guidelines and checklist (4). Contingent valuation studies within quidditch sports medicine were identified using search terminologies that combined the following epidemiological terms: quidditch injuries, quidditch concussions, returnto-play quidditch, quidditch incidences. Variations of the terms were also used when deemed necessary by the reviewers (e.g. "injury" vs. "injuries").

The initial search yielded 698 articles. Duplicates were removed, and each article was reviewed for the following inclusion criteria: English language, pertained to quidditch related injuries, and full-text (Figure 1). To further ensure that all appropriate studies were identified, the reference list of each identified study was also reviewed, and no further articles met the inclusion criteria. The studies included in qualitative synthesis yielded five articles (Table 1).

\section{3 | RESULTS}

\section{1 | Overview of Study Characteristics}

Following review, two articles were identified as prospective injury epidemiological studies based on their inclusion of injury epidemiology, which was composed of various injury types (i.e. fractures, sprains) (5, 6). Two other studies were identified as primarily concussion studies for their inclusion of injury epidemiology which only recorded concussions $(7,8)$. One article fit the review's inclusion criteria, but focused on radiological epidemiology study through evaluation of six radiology cases and was non-peer reviewed (9). While there were no inclusion criteria for the publication date, all studies were from the past three years. Beidler et al. and Brezinski et al. included other sports in addition to quidditch. Quidditch injury data were isolated from articles with multiple sports injury data sets during the review.

\section{2 | Injury Data}

Pennington et al. (5) reported 315 injuries to 180 athletes ( $n=348$ total respondents), with an overall incidence of 4.06 injuries per 1000 hours. Brezinski et al. (6) reported 16.2 per 1000 athlete-exposures ( $n=25$ quidditch respondents). In general, an athlete exposure is "one athlete participating in one practice or competition during which the athlete was exposed to the possibility of athletic injury" (13). Pennington et al. noted in their study that players were to report average hours played per week instead of exposures as the nature of a quidditch match makes it difficult to measure the exact time of a game being completed. Unlike other sports, matches in quidditch do not abide by a certain time period, and quidditch matches end after the snitch is caught, thus creating variability in the actual time played. Pennington et al. also noted that players of higher skill were likely to report higher injury rates, using the identifying variable of "skill" in their survey questionnaire. However, it should be noted that survey questionnaires were not available for analysis for all of the 


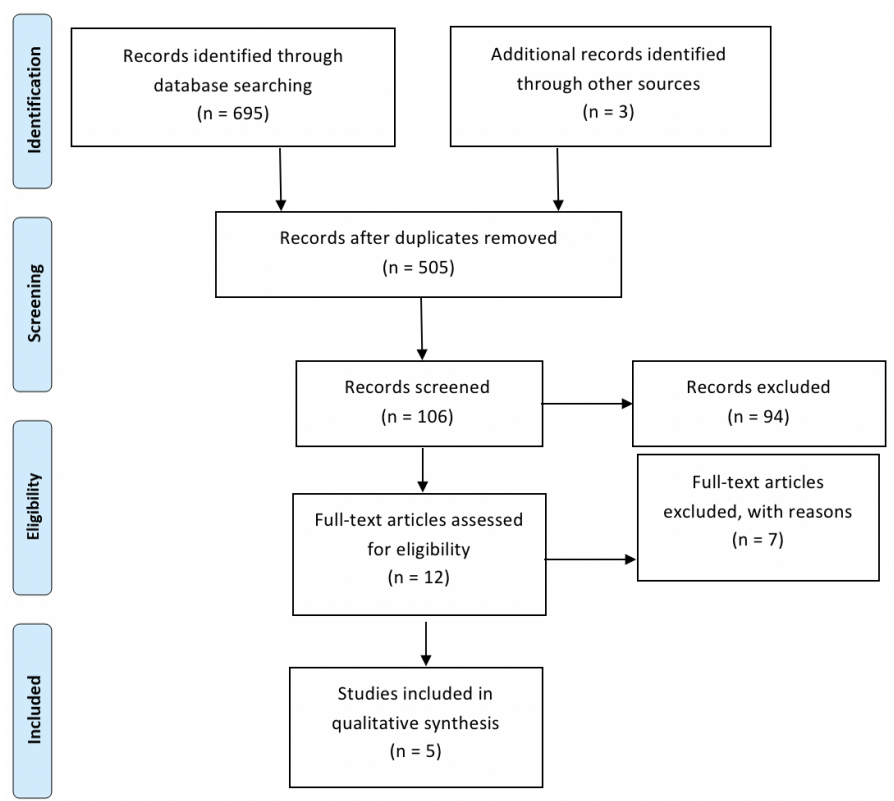

FIGURE 1 Flowchart of the study selection process. Initial search criteria produced 695 articles of which ultimately 5 studies were included.

\begin{tabular}{|c|c|c|c|c|c|c|c|}
\hline AUTHOR & JOURNAL & YEAR & $(n=)$ & $\begin{array}{l}\text { Additional sports } \\
\text { included in study }\end{array}$ & Injury Rate & $\begin{array}{l}\text { Concussic } \\
\text { analysis }\end{array}$ & $\begin{array}{l}\text { Body Region of } \\
\text { most incidence }\end{array}$ \\
\hline $\begin{array}{l}\text { Pennington } \\
\text { et al. }\end{array}$ & $\begin{array}{l}\text { International Journal of } \\
\text { Sports Physical Therapy }\end{array}$ & 2017 & 348 & NO & $\begin{array}{l}4.06 \text { injuries } \\
\text { per } 1000 \\
\text { hours }\end{array}$ & YES & $\begin{array}{c}\text { Head \& } \\
\text { Extremities }\end{array}$ \\
\hline $\begin{array}{l}\text { Tsakok } \\
\text { et al. }\end{array}$ & $\begin{array}{c}\text { European Society of } \\
\text { Musculoskeletal } \\
\text { Radiology }\end{array}$ & 2017 & 12 & NO & - & * & Upper Limb \\
\hline $\begin{array}{l}\text { Beidler } \\
\text { et al. }\end{array}$ & $\begin{array}{c}\text { Journal of Athletic } \\
\text { Training }\end{array}$ & 2018 & 10 & YES & - & YES & $* *$ \\
\hline $\begin{array}{c}\text { Tran et } \\
\text { al. }\end{array}$ & $\begin{array}{l}\text { Journal of the } \\
\text { Neurological Sciences }\end{array}$ & 2019 & 157 & NO & - & YES & ** \\
\hline $\begin{array}{l}\text { Brezinski } \\
\text { et al. }\end{array}$ & $\begin{array}{l}\text { Athletic Training and } \\
\text { Sports Health Care }\end{array}$ & 2020 & 25 & YES & $\begin{array}{c}16.2 \text { per } \\
1000 \text { athlete- } \\
\text { exposures }\end{array}$ & YES & *** \\
\hline
\end{tabular}

* Study was a radiological examination and indicated "neck" injuries which reviewers may consider potential for concussions though not explicitly stated

** Studies were focused primarily on concussion epidemiology.

*** Unavailable.

TAB LE 1 Overview of study characteristics including injury rate, concussion analysis, and body region of most incidence. 
studies included in this review. This study noted that head injuries ( $n=86)$ and lower $(n=97)$ and upper extremity $(n=85)$ injuries had the highest prevalence, whereas pelvic injuries had the lowest $(n=2)$ prevalence. It is also noteworthy that the studies used the traditional variables for sex (male and female).

\section{3 | Concussion Data}

The study by Beidler et al. (8) was not focused on documenting player injuries, but rather used a survey questionnaire to observe knowledge of sports-related concussion signs and symptoms. Within this study, there were six quidditch players, which presents a limitation as this cannot be considered a significant representation of the quidditch community as a whole. Tran et al. (7) noted that of the players with head injuries, only $39 \%$ sought medical treatment. Tsakok et al. (9) evaluated radiological examinations of quidditch player injuries, but the epidemiology was not defined by injury type as seen in the Pennington et al. (5) and Brezinski et al. (6) studies. However, the radiology determined that $25 \%$ of its quidditch player injuries were considered neck injuries. This is important when considering that concussion knowledge data in the Beidler et al. (8) study showed that only $27.6 \%$ of the sports athletes were aware that neck pain is a sign of a concussion. Pennington et al. (5) also stated that the overall rate of concussions in males was $0.651 / 1000$ hours and in females was $1.163 / 1000$ hours $(0.877 / 1000$ hours overall). The reviewers were not able to identify such quidditch-isolated values in the Brezinski et al. (6) study.

\section{4 | DISCUSSION}

The game of quidditch is both mentally and physically demanding of its players. The overall epidemiological literature of quidditch injuries is minute and often combined within other variables to add significance to their study. Moreover, it is imperative to conduct future studies specific to the sport of quidditch. The most prominent study the reviewers noted was the Pennington et al. article for including the largest population of quidditch players, with a methodology corresponding to injury surveillance literature similar to rugby and lacrosse studies. The injury rates seen in the two studies were found to be lower than those seen in rugby $(46.8 / 1000$ player hours) or American football competitions (36.94/1000 athlete exposures) (3, 10). However, the aforementioned variability among "player hours" and "athlete exposures" makes it difficult to draw conclusions towards comparing the safety across sports. On the other hand, the results of this study can also suggest that quidditch is a safer sport, which can help to serve as an example for concussion and injury protocols found in other leagues. However, the data presented by Pennington et al. cannot encompass quidditch play internationally due to the variation of gameplay among the different quidditch leagues.

Concussion data between studies were too limited to allow for significant conclusions to be drawn on concussion epidemiology in quidditch. Beidler et al. (8) established the need to further educate quidditch players on concussion symptoms. Additionally, there is significant literature showing head cap protection does not decrease injury rates among football and lacrosse players, however, it is not possible to apply such a conclusion on quidditch players without direct investigation $(11,12)$. It is also possible that the nature of the sport could imply lower concussion rates compared to others due to the unique tackling method in quidditch, as tackling is conducted while holding onto a stick, or "broom", in the game. This may have a significant effect in preventing head collisions. Moreover, this warrants future investigation for a large scale concussion study among quidditch players.

In conclusion, this study addresses the current state of the literature on an emerging novelty sport. While initial studies on the safety of quidditch are encouraging, it is difficult to draw precise conclusions due to the smaller sample size of players compared to studies on other sports. Moreover, the variability among rules of play, gender inclusivity, and variation of multiple leagues suggests a need for the development of future collaborative concussion and injury epidemiological studies to 
provide further literature and recommendations to the quidditch community.

\section{5 | ACKNOWLEDGEMENTS}

The authors would like to acknowledge Megan Anderson, Strategic Planning Manager, \& Mary Kimball, executive director of US Quidditch for permission to launch our Quidditch Injury Control Knowledge (QUICK) Initiative Study.

\section{REFERENCES}

1. US Quidditch. About US Quidditch [Internet]. 2020. [cited 2020 May 2]. Available from: https://www.usquidditch.org/ about/mission/

2. US Quidditch. Enforcement of the Gender Maximum Rule During Gameplay [Internet]. 2020. [cited 2020 May 2]. Available from: https://www.usquidditch.org/about/rules

3. Yeomans C, Kenny IC, Cahalan R, Warrington GD, Harrison $A J$, Hayes $K$, et al. The incidence of injury in amateur male rugby union: A systematic review and meta-analysis. Sports Med. 2018;48(4):837-48.

4. Moher D, Liberati A, Tetzlaff J, Altman DG, Group P. Preferred reporting items for systematic reviews and meta-analyses: the PRISMA statement. Int J Surg. 2010;8(5):336-41.

5. Pennington R, Cooper A, Edmond E, Faulkner A, Reidy MJ, Davies PSE. Injuries in quidditch: A descriptive epidemiological study. Int J Sports Phys Ther. 2017;12(5):833-9.

6. Brezinski T, Martin J, Ambegaonkar J. Prospective injury epidemiology in competitive collegiate club sports, quidditch, and ultimate frisbee. Athletic Training and Sports Health Care. 2020.

7. Tran Y, Walser S, Wayland J, Elwood A, Posas J. Catching the snitch or the consequences? Profiling incidence of concussions in quidditch players. Neurology. 2018;91:S24.3-S5.

8. Beidler E, Bretzin A, Hanock C, Covassin T. Sport-related concussion: Knowledge and reporting behaviors among collegiate clubsport athletes. J Athl Train. 2018;53(9):866-72.

9. Tsakok M, Peschl H, Partington $\mathrm{K}$. The radiological spectrum of quidditch injuries - a 5-year retrospective review. European Society of Musculoskeletal Radiology. 2017.

10. Kerr ZY, Simon JE, Grooms DR, Roos KG, Cohen RP, Dompier TP. Epidemiology of football injuries in the national collegiate athletic association, 2004-2005 to 2008-2009. Orthop J Sports Med. 2016;4(9):2325967116664500.

11. Withnall C, Shewchenko N, Wonnacott M, Dvorak J. Effectiveness of headgear in football. Br J Sports Med. 2005;39 Suppl 1(Suppl 1):i40-8
12. Veasley S, Baron SL, Nguyen M, Anil U, Alaia M, Cardone D, Testa N. Effectiveness of high school girls lacrosse headgear mandate in the reduction of head and face injuries. Orthop J Sports Med. 2019;7(3 Suppl):2325967119S00026.

13. Comstock RD, Gilchrist J. Sports-Related Injuries Among High School Athletes - United States, 2005-06 School Year [Internet]. 2006. [cited 2020 Nov 2]. Available from: https://www.cdc.gov/mmwr/preview/mmwrhtml/mm5538a1.htm 